\title{
TRANSTORNO DESAFIADOR DE OPOSIÇÃO (TDO) E ALTAS HABILIDADES/SUPERDOTAÇÃO (AH): UMA INTERVENÇÃO PSICOPEDAGÓGICA DE BASE COGNITIVO COMPORTAMENTAL
}

\author{
Maria Claudia Dutra Lopes Barbosa \\ Bacharel e licenciada em Letras - UFRJ; Especialista em Educação Especial - UERJ; Mestre pela Faculdade de \\ Educação - UERJ; Doutora pela Faculdade de Ciências Médicas - UERJ; Professora de Educação Especial \\ FAETEC/RJ; Psicopedagoga; Psicóloga; Terapeuta Cognitivo-Comportamental \\ $\triangle$ mclaudiadutra@gmail.com
}

\begin{abstract}
Resumo
Este artigo tem por objetivo discutir os vários instrumentos adotados pela abordagem cognitivo-comportamental, no atendimento psicopedagógico de uma criança com transtorno desafiador de oposição e altas habilidades. A partir do diagnóstico realizado por um neuropediatra, relativo ao transtorno desafiador de oposição, instrumentos foram introduzidos no processo psicopedagógico, tais como a Investigação das cognições, emoções e ações; a Economia de fichas; a Parada na ação indesejada e o Cartão de informe, com vistas a promover o decréscimo do comportamento disruptivo da criança pesquisada. No que diz respeito ao comportamento relativo às altas habilidades, foram introduzidas a Lista de Características de Altas Habilidades; as Matrizes Progressvas de Raven e o Modelo Triádico de Renzulli \& Mönks. Os resultados da pesquisa registraram decréscimo do comportamento relativo ao transtorno desafiador de oposição e a expressão do comportamento relativo às altas habilidades/superdotação.
\end{abstract}

Palavras-chave: transtorno desafiador de oposição; altas habilidades; abordagem psicopedagógica de base cognitivo-comportamental.

\section{OPPOSITIONAL DEFIANT DISORDER AND HIGH ABILITIES: A PSYCHOEDUCATIONAL COGNITIVE-BEHAVIORAL INTERVENTION}

\begin{abstract}
This article intends to discuss the cognitive-behavioral instruments adopted by psychoeducacional clinical procedure which was applied to an oppositional defiant behavior child, who is also a high ability student. Considering the neuropediatrician's diagnosis related to oppositional defiant behavior, it was introduced psycoeducational instruments as Cognition, emotion, acting investigation; Token economy; Stopping rejected acting, and Information card, in order to promote the disruptive child behavior decrease. Concerning to high abilities behavior, it was introduced High Abilities Characteristics List; Raven Progressive Matrices, and Renzulli \& Mönks Triadic Model. The researching results registered oppositional defiant behavior decrease, and high abilities behavior expression.
\end{abstract}

Keywords: oppositional defiant behavior; high abilities; cognitive-behavior psychoeducational approach 


\section{INTRODUÇÃO}

O presente artigo objetiva discutir procedimentos de intervenção psicopedagógica pautados nas técnicas referentes à Terapia Cognitivo-Comportamental, junto a uma criança de oito anos que apresenta o transtorno desafiador de oposição e altas habilidades/superdotação. Em razão deste transtorno, deve-se destacar o fato de que a mencionada criança revela não só queda no rendimento escolar como também apresenta aprisionamento da expressão das habilidades referentes à superdotação, em razão do TDO.

Cumpre ressaltar que um dos maiores problemas relacionados ao TDO diz respeito ao controle da agressividade, diante de situações que demandam obediência a regras por parte da criança, provocando na mesma irritação e frustração, consequentemente, ataque a quem a impede de ter acesso ao que deseja (SERRA-PINHEIRO et al. 2004).

\section{Conceituando o transtorno desafiador de oposição}

Deve-se ressaltar que estas crianças apresentam um quadro clínico sugestivo de maiores cuidados, por exibirem recorrentes comportamentos de desobediência, desafio e hostilidade em relação às figuras de autoridade. Pontua-se, também, que a criança com o transtorno desafiador de oposição deve ser assim considerada, ao apresentar este tipo de perfil, no mínimo, por seis meses (LUISELLI, 2005).

Segundo a Classificação do DSM-IV- TR (APA, 2014) o transtorno desafiador de oposição se encaixa na mesma categoria de "Transtornos do déficit da atenção e do comportamento perturbador", incluído na sessão "Transtornos geralmente diagnosticados na infância ou adolescência” (DSM - IV-TR, 2000). Consideram-se oito os critérios de ocorrência frequente deste comportamento, segundo o DSM - IV - TR para o TDO. São eles:

\footnotetext{
“... perder a calma; discutir com adultos; negar-se a obedecer aos pedidos ou regras dos adultos; fazer coisas que incomodem, gratuitamente, os outros; culpar os outros por seus erros ou comportamentos inadequados; ser suscetível à irritação; ficar enraivecido e ressentido; ser rancoroso e vingativo" (DSM- IV- TR, 2000).
}

Considerando-se a necessidade de se fazer um diagnóstico, em termos de manifestação, o transtorno se apresenta em casa, na escola e em lugares públicos, revelado diferentes teorias que justifiquem seu surgimento.

\section{Teorias sobre suas possíveis causas}

Evidências existem, indicando que o TDO se apresenta moldado e mantido pela natureza das relações entre a criança e os adultos importantes de seu meio. Destacam-se, por 
esta razão, o temperamento da mesma, com ênfase na rabugice e na dificuldade que esta revela em se acalmar, assim como para a presença de psicopatologia parental, com foco em problemas familiares emocionais e de isolamento social; problemas econômicos; táticas educacionais inadequadas ou inconsistentes, entre outros fatores (KAPLAN et al., 2003).

\section{Conceituando as altas habilidades/superdotação}

A identificação do indivíduo com altas habilidades demanda alguns procedimentos cautelosos de observação continuada que são realizados, a partir do preenchimento de alguns questionários sobre os interesses que este educando revela em determinadas áreas, tendo-se o cuidado de acompanhar os comportamentos de destaque nas áreas específicas de expressão de talentos da pessoa em questão. Alguns instrumentos disponíveis para auxiliar o educador nesta identificação podem ser utilizados, como: as Escalas de Renzulli - SCRBSS (RENZULLI, 2001); a lista de Características dos Estudantes Superdotados/Talentosos (METTRAU, 2001); a Lista de Características de Altas Habilidades (GUENTHER, 2000), além da observação contínua do professor, pautada em leituras na área de altas habilidades, uma vez que “... Gagné demonstra que os professores são perfeitamente capazes para detectar sinais de talento nas crianças, o que vem a ser confirmado por outros estudos" (Idem, p. 93).

$\mathrm{O}$ uso de testes psicológicos, especificamente aqueles relativos à mensuração da inteligência do indivíduo talentoso, são aplicados apenas por psicólogos. O teste MM (Minhas Mãos, de Helena Antipoff, 2002), em termos de identificação do educando com altas habilidades, oferece abundantes e inúmeros quesitos a serem avaliados, apresentando por isso mesmo, finalidades múltiplas. Entre tantas possibilidades, há aquelas pertinentes à fluência ideativa do educando talentoso, sua criatividade, o uso que faz de analogia e metáforas, entre outras especificidades. Ele pode ser aplicado por um educador, desde que este tenha profundo domínio de Língua Portuguesa.

Lembrando a questão dos testes psicológicos, quando a instituição conta com a presença destes profissionais em seu quadro, pode-se fazer uso deste tipo de instrumento de avaliação da inteligência. Geralmente, são utilizadas as Matrizes Progressivas de Raven Escala Geral (RAVEN, 2000), sempre lembrando que os testes não têm a função de excluir os indivíduos do processo seletivo, uma vez que tais instrumentos não são capazes de contemplar todos os tipos de habilidades apresentadas pelos estudantes talentosos (BRASIL, 1999).

Prosseguindo-se na identificação dos indivíduos com altas habilidades/superdotação/talentos, merece destaque o Modelo dos Três Anéis de Renzulli e Mönks (METTRAU, 2000), conforme ilustração abaixo, que oferece possibilidades ao 
educador de compreender as características de altas habilidades, a partir da observação do mencionado modelo, cujos anéis juntos, promovem uma intersecção na qual se encontra o indivíduo com altas habilidades/superdotação/talentos.

Cada anel apresenta, no seu interior, uma característica específica, sendo o primeiro concernente ao envolvimento com a tarefa, que quer dizer do comprometimento do educando com aquilo que ele faz, fazendo-o com afinco e dedicação, em razão da constância de suas ações; o segundo diz respeito à(s) habilidade(s) acima da média, expressa(s) pelo educando, de tal modo, que este se destaca dos demais; o terceiro anel é o da criatividade, que ressalta o fato de que o produto criado pelo indivíduo foge à regra, por apresentar características de expressiva criatividade, sendo esta tomada como algo diferente e único.

A expressão de seus talentos é vista e reconhecida, socialmente, nas pontas do triângulo equilátero, onde se lê, no vértice esquerdo, colégio, no direito, companheiros e no inferior, família (METTRAU, 2000).

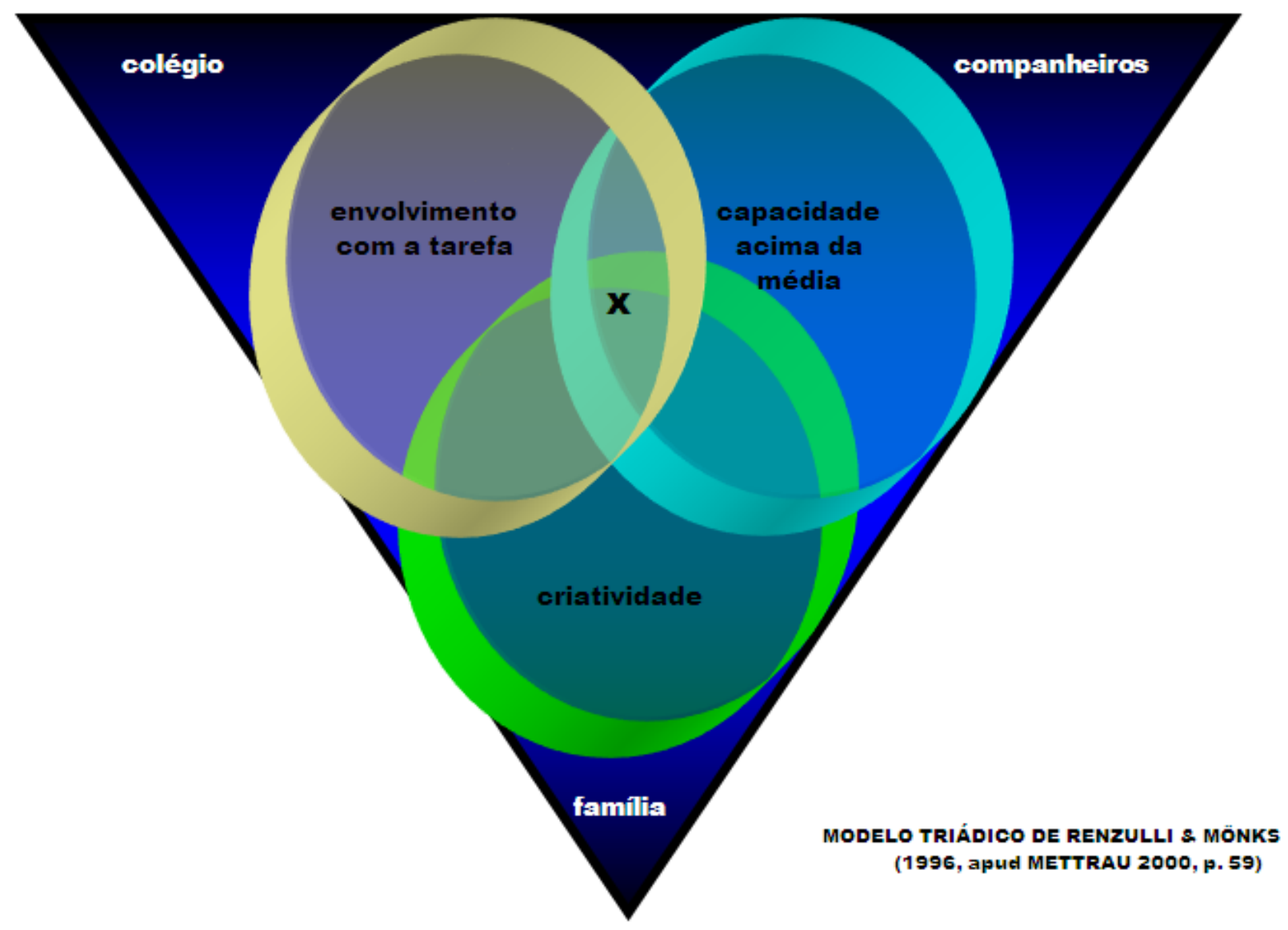

A manifestação natural das habilidades, que ocorre com o indivíduo que apresenta talentos, precisa ser considerada como algo a ser potencializado. O bem-estar, a concentração da atenção e o envolvimento que este demonstra, sem perder a disposição ou apresentar 
cansaço, enquanto cria algo, também ocorre em artistas, escritores, cientistas, que se dedicam à sua atividade favorita, porque "o fluxo tende a ocorrer quando as habilidades de uma pessoa estão totalmente envolvidas em superar um desafio que está no limiar de sua capacidade de controle..." (CSIKSZENTMIHALYI, 1999, p. 37). Ademais, experiências eficientes resultam do equilíbrio entre a capacidade de ação do indivíduo e as oportunidades que lhe são ofertadas para agir. Assim, a busca em conhecer as áreas de maior potencial destes estudantes, atuando, diariamente, no sentido de lhes favorecer o desenvolvimento das mesmas, deve ser o maior objetivo dos educadores que têm sob sua responsabilidade educandos superdotados (PADRÓN, 2000).

\section{MÉTODO}

Optou-se, para desenvolver esta pesquisa, pela adoção do método estudo de caso, pelo fato deste se basear em “... generalizações analíticas sobre as quais o pesquisador está tentando ampliar um conjunto particular de resultados a alguma teoria mais abrangente"... (YIN, 2001, p. 58). Segundo Stake (1995), o estudo de caso pode ser único ou múltiplo, e a unidade de análise vai de um indivíduo a uma ou mais organizações. Por esta razão, justificase a escolha efetuada, ressaltando-se que as altas habilidades perfazem o quantitativo de "... 3\% a 5\% da população" (GUENTHER, 2000, p. 30), e o transtorno desafiador de oposição é encontrado em $6 \%$ da população infanto-juvenil (SERRA-PINHEIRO et al. 2004).

Deve-se ressaltar que, tratando-se de uma criança que apresenta as duas características acima expressas, foi necessário trabalhar, primeiramente, na promoção do decréscimo da manifestação do TDO, uma vez que este comprometeu a expressão e o curso do segundo, afetando, inclusive, as relações sociais do indivíduo.

\section{PARTICIPANTE}

A pesquisa foi desenvolvida apenas com um único indivíduo, na Clínica Psicopedagógica, demandando uma dupla intervenção, sendo a primeira pertinente ao TDO e a outra às Altas Habilidades.

\section{INSTRUMENTOS UTILIZADOS}

Uma vez que houve a confirmação do diagnóstico de TDO, por parte do neuropediatra da criança, a partir dos comportamentos pertinentes ao desafio às regras, ao padrão de intensa irritabilidade, rancor e vingança (DSM-IV, 2000), sendo utilizados, para levantamento das consequências negativas advindas do mesmo, instrumentos de avaliação de eventos 
deflagradores do comportamento desafiador, registrados em dia e hora de ocorrência; situação; pensamentos “quentes”, pertinentes à situação vivida (STALLARD, 2006). Estes elementos de análise foram assim considerados, porque estariam envolvidos com a situação e os sentimentos experimentados, permitindo, portanto, que fossem identificadas as crenças que subjazem às situações-problema.

Paralelo ao trabalho acima descrito, a técnica de Economia de Fichas foi introduzida, na condição de um instrumento eficaz no incentivo ao automonitoramento do comportamento socialmente adequado a se instalar (CABALLO, 2002).

No que diz respeito às $\mathrm{AH}$, foi utilizada a Lista de Características de Altas Habilidades (GUENTHER, 2000), bem como foram ultiizadas as Matrizes Progressivas de Raven e o Modelo Triádico de Renzulli \& Mönks (METTRAU, 2000).

\section{PROCEDIMENTOS PARA COLETA DE DADOS}

Os instrumentos utilizados para serem avaliados os comportamentos TDO permitiram averiguar as questões pertinentes aos pensamentos disfuncionais do indivíduo, pois “... é útil para o clínico adotar o papel do caçador de pensamentos [...], identificando as cognições importantes, quando elas ocorrem" (STALLARD, 2004, p. 38). No que diz respeito às AH, foram aplicadas as Matrizes Progressivas de Raven, com vistas a avaliar o raciocínio lógico do estudante, considerando-se sua habilidade para imaginar figuras de encaixe, ordenação de posições das mesmas, suas sequências e combinações (BARBOSA, 2008).

\section{PROCEDIMENTOS PARA TRATAMENTOS DE DADOS}

A partir dos comportamentos agressivos advindos das crenças disfuncionais apresentadas pelo individuo da pesquisa, foram identificados o tipo de situação ocorrida; o tipo de crença relacionada à situação vivida; o padrão de resposta emitido para a situação e o desfecho da mesma, considerando-se o ambiente familiar e escolar, e, analisando-se o material, segundo a teoria das Habilidades Sociais (CABALLO, 2006; DEL PRETTE \& DEL PRETTE, 2005), lembrando que “... o sentimento pode ser um fator negativo sobre a capacidade de resolver um problema, se a criança não apresentar um mínimo de controle emocional e inibição da impulsividade" (DEL PRETTE \& DEL PRETTE, 2005, p. 204).

No tocante aos comportamentos relativos às altas habilidades, foi realizado um levantamento dos mesmos, a partir da Lista de Características de Altas Habilidades (GUENTHER, 2000), das Matrizes Progressvas de Raven (RAVEN, 2000), e do Modelo Triádico de Renzulli \& Mönks (METTRAU, 2000). 


\section{RESULTADOS E DISCUSSÕES}

Fez-se de suma importância entender as causas do comportamento inadequado da criança, a partir da identificação das situações deflagradoras do mesmo, objetivando a orientação dos pais da mesma, pautando-se em um questionário elaborado por eles. Tornou-se relevante, da mesma forma, desenvolver nos pais e na criança a atenção firme entre estes, enquanto falavam, de forma eficaz e duradoura. Ressalte-se, também, que a necessidade de se aumentar a obediência da criança às regras parentais e escolares, tanto quanto a frequência da brincadeira independente representaram elementos de sucesso no trabalho psicopedagógico.

Tabela 1: Investigação das cognições, emoções e ações

\begin{tabular}{|l|l|l|}
\hline $\begin{array}{l}\text { O QUE EU PENSEI } \\
\text { QUANDO... }\end{array}$ & O QUE EU SENTI QUANDO... & O QUE EU FIZ QUANDO... \\
\hline $\begin{array}{l}\text { Algum colega passou a minha } \\
\text { frente na fila; }\end{array}$ & $\begin{array}{l}\text { Senti raiva, porque quero ser o } \\
\text { primeiro; }\end{array}$ & Dei socos e pontapés nele; \\
\hline $\begin{array}{l}\text { Quando quis ir ao banheiro, } \\
\text { novamente, mas a professora não } \\
\text { deixou; }\end{array}$ & $\begin{array}{l}\text { Raiva, porque ela não podia me } \\
\text { impedir; }\end{array}$ & $\begin{array}{l}\text { Mordi a perna da professora e botei } \\
\text { tudo pra fora da calça, e disse que ia } \\
\text { fazer xixi no corredor; }\end{array}$ \\
\hline $\begin{array}{l}\text { Eu perdi a partida, no jogo com o } \\
\text { meu pai; }\end{array}$ & $\begin{array}{l}\text { Raiva, porque eu tenho que ganhar } \\
\text { sempre; }\end{array}$ & $\begin{array}{l}\text { Eu quebrei as coisas que estavam na } \\
\text { minha frente; }\end{array}$ \\
\hline $\begin{array}{l}\text { Quando minha mãe me mandou } \\
\text { dormir. }\end{array}$ & $\begin{array}{l}\text { Eu fiquei com raiva e frustração, } \\
\text { porque queria ver o filme. }\end{array}$ & \begin{tabular}{l} 
Joguei os meus chinelos pela janela. \\
\hline
\end{tabular}
\end{tabular}

A partir da tabela acima descrita, os comportamentos relativos à raiva e à frustração foram diminuindo, de modo que após dez sessões de trabalhos de técnicas de enfrentamento, houve decréscimo de $75 \%$ nos mesmos. Ressalta-se, igualmente, o valor metodológico da adoção da técnica de Economia de Fichas, que se consistiu na troca de fichas contendo o número 1 (um) em cada uma delas, a partir da expressão, por parte da criança, de um comportamento socialmente valorizado. Quando a criança atingiu 10 (dez) fichas, estas foram trocadas por um objeto de sua preferência, no caso, as Revistas Recreio, em razão das mesmas apresentarem artigos de interesse das crianças com AH. Durante todo o processo de uso de instrumentos de incentivo ao automonitoramento do comportamento socialmente adequado (CABALLO, 2002), é importante ressaltar que foram trabalhados os conceitos de ética, direitos e deveres, presentes na teoria das Habilidades Sociais (CABALLO, 2006). 
Tabela 2: Economia de fichas

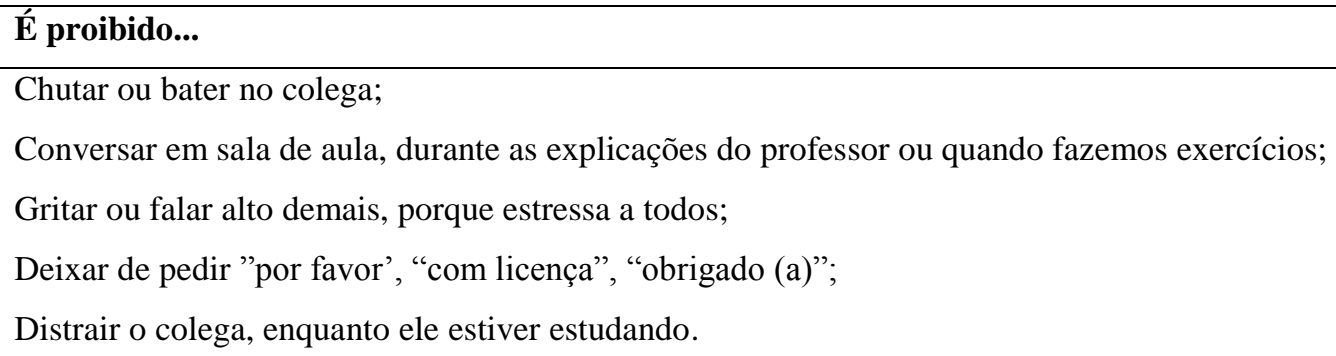

No que diz respeito aos comportamentos relativos às habilidades sociais na escola, o indivíduo da pesquisa, após oito semanas de trabalho, revelou um decréscimo de $87 \%$ da produção de comportamentos inadequados ao ambiente escolar.

Buscando-se outra forma de auxiliar a criança a conter o comportamento indesejado, utilizou-se o time out, conhecido como "parada na ação indesejada" (STALLARD, 2006), considerando-se como parâmetro de tempo, tantos minutos quantos são os anos de vida da criança. Assim sendo definiu-se, junto com os pais, o quarto do menino como lugar de permanência, a fim de acalmá-lo.

Tabela 3: Parada na ação indesejada (time out)

\begin{tabular}{|l|l|l|}
\hline ACONTECIMENTO & $\begin{array}{l}\text { INTERRUPÇÃO NO CURSO DA } \\
\text { AÇÃO }\end{array}$ & AVALIAÇÃO DA ESTATÉGIA \\
\hline Gritou com a mãe; & Foi para o quarto, por 8 min. & $\begin{array}{l}\text { Acalmou-se, e foi indagado sobre o } \\
\text { que refletiu, acerca do ocorrido. Ele } \\
\text { pôde, enfim, dialogar com a mãe. }\end{array}$ \\
\hline $\begin{array}{l}\text { Respondeu, grosseiramente, ao } \\
\text { pai. }\end{array}$ & Foi para o quarto, por 8 min. & $\begin{array}{l}\text { Acalmou-se. Teve condições de } \\
\text { conversar com o pai sobre o } \\
\text { ocorrido. }\end{array}$ \\
\hline
\end{tabular}

Este procedimento resultou em um ganho interessante para a criança, desenvolvendo na mesma a noção do afastamento da situação difícil, com o controle emocional, para buscar alternativas de solução. Desta forma, após quatro semanas de adoção deste procedimento, o menino respondia, de maneira natural e reflexiva, diante das situações, em $89 \%$ das situações.

Procedeu-se, como medida de desenvolvimento de raciocínio preditivo de automonitoramento, a antecipação às situações-problema, trabalhando-se os comportamentos adequados da criança, antes de sua ocorrência, a partir do reforço (com elogios, sorrisos e enaltecimentos, acerca da importância do respeito a si e aos outros), procurando a expressão e a manutenção contínua deste comportamento no repertório da criança. Buscou-se, para 
melhorar a atuação desta na escola, em termos de automonitoramento, o uso de um cartão de informe diário do comportamento que a mesma aplicava a si, na escola (CABALLO, 2002).

Tabela 4: Cartão de informe

\begin{tabular}{|l|l|l|}
\hline SITUAÇÃO ANTECIPADA & $\begin{array}{l}\text { RESOLUÇÃO DO } \\
\text { PROBLEMA }\end{array}$ & $\begin{array}{l}\text { AVALIAÇÃO DOS } \\
\text { RESULTADOS }\end{array}$ \\
\hline $\begin{array}{l}\text { Vou jogar futebol na escola, e o colega } \\
\text { vai fazer gol, e eu não vou gostar; }\end{array}$ & $\begin{array}{l}\text { Preciso aplicar a técnica de } \\
\text { respiração, para não bater no } \\
\text { colega; }\end{array}$ & POSITIVO \\
\hline $\begin{array}{l}\text { Não consigo ficar sentado, quando acabo } \\
\text { os deveres, porque quero conversar; }\end{array}$ & $\begin{array}{l}\text { Vou levar um livro interessante } \\
\text { para ler; }\end{array}$ & NEGATIVO \\
\hline $\begin{array}{l}\text { Se a professora me colocar de castigo, } \\
\text { porque eu desobedeci; }\end{array}$ & $\begin{array}{l}\text { Vou aplicar a técnica de } \\
\text { respiração, para não responder à } \\
\text { professora. }\end{array}$ & POSITIVO \\
\hline
\end{tabular}

O resultado positivo do uso deste cartão de informe se fez presente, em $80 \%$ das vezes, a partir de um comportamento de previsão e reflexão socialmente esperados, que se manifestaram. Assim, pode-se dizer que se trata de um procedimento de enorme valia, orientar a criança a avaliar suas percepções sobre o mundo, suas interpretações acerca dos acontecimentos da vida e suas atribuições sobre seu comportamento, buscando, concomitantemente, discutir com ela conceitos referentes à ética e cidadania na vida e na escola. Paulatinamente, progrediu-se com o uso dos cartões de informe, para situações de interações sociais em trabalhos com outras crianças, com a família e na escola, a partir da adesão parceira e colaboradora da professora. Trata-se de uma forma de apoio e auxílio, não uma punição (LUISELLI, 2005).

Ressalta-se, aqui, que ensinar à criança a enfrentar situações difíceis e responder a acontecimentos desencadeadores, por meio da autoverbalização, em voz alta, durante jogos ou nos encontros psicopedagógicos, conduzirá a mesma a desenvolver a atenção à própria voz e vontade. Foi possível, mais adiante, desenvolver nesta criança a fala sussurrante (autoverbalização), como um jogo de treinamento da atenção à fala, em voz baixa, no lugar da fala em voz alta, sob a orientação da psicopedagoga. Vale lembrar, também, a importância de se ter procedido à simulação da situação-problema referente ao comportamento inadequado da criança, solicitando que a mesma utilizasse, apenas, o pensamento. Fez-se uso de elogios, como forma de reforço, tão logo esta expressava o comportamento adequado (LUISELLI, 2005). 


\section{Comportamentos relativos às altas habilidades}

Foram aplicadas as Matrizes Progressvas de Raven no indivíduo da pesquisa, registrando-se o percentual > 95\%, indicativo de “... inteligência superior” (RAVEN, 2000, p. 19), muito embora esta se encontrasse difícil de ser explorada, em razão do quadro agressivo no qual se encontrava a criança. Mais adiante, a Lista de Características de Altas Habilidades (GUENTHER, 2000) foi aplicada ao indivíduo, após o trabalho de base cognitivocomportamental, pelo mesmo motivo anteriormente mencionado, relativo ao comportamento desafiador. Assim sendo, registraram-se os seguintes resultados:

TABELA 5: Indicadores de altas habilidades/superdotação

\begin{tabular}{l|l}
\hline \multicolumn{2}{c}{ ALTAS HABILIDADES/SUPERDOTAÇÃO } \\
\hline 2- um dos melhores nas áreas de matemática e ciências; & $\begin{array}{l}\text { 10- um dos mais persistentes, compromissados, por } \\
\text { chegarem ao fim do que fazem; }\end{array}$ \\
\hline 3- um dos melhores nas áreas de artes e educação artística; & $\begin{array}{l}\text { 11- um dos mais independentes, pois inicia seu trabalho } \\
\text { sozinho e o faz sem solicitar ajuda; }\end{array}$ \\
\hline 4- um dos melhores em atividades extracurriculares; & 13- um dos mais originais e criativos; \\
\hline 6- um dos mais curiosos, interessados, perguntadores; & 18- um dos mais capazes em pensar e tirar conclusões; \\
\hline $\begin{array}{l}\text { 7- um dos mais participantes e presentes em tudo, dentro e } \\
\text { fora da sala de aula; }\end{array}$ & 20- um dos mais solitários e ignorados; \\
\hline \begin{tabular}{l} 
8- um dos mais críticos com os outros e consigo mesmo; \\
\hline $\begin{array}{l}\text { 9- um dos que revela melhor memória, por aprender e fixar } \\
\text { com facilidade; }\end{array}$
\end{tabular} & $\begin{array}{l}\text { 24- um dos que se destacam em termos de habilidades } \\
\text { manuais e motoras; }\end{array}$ \\
\hline
\end{tabular}

O comportamento relativo às altas habilidades na criança pesquisada se fez indentificar, em todos os itens da lista acima exposta, sobretudo nas áreas de interesse, como matemática e ciências, a partir das leituras relativas a foguetes desenvolvidas na escola, e da construção de pequenos robôs, com o auxílio da família, além da área da criação literária, representada pelo fragmento de história descrito a seguir:

\section{TÍTULO: Ilusão}

"Moforroque é um planeta onde há muitas pedras, e, nelas, se escondem dinossauros. Ao pousar no solo deste desconhecido planeta, o astronauta se deparou com os "dinoroques", pedras que se transformavam em dinossauros.

Pisar em Moforroque foi um engano, na verdade, ele deveria ter pousado em Concomeque, para se encontrar com o chefe dos concomequinos. Que saudades da Terra, pensava Teo...”

Considerando-se a criatividade como uma dimensão da inteligência (METTRAU, 2000), deve-se apontar para o fato de que o processo criativo da criança fluiu com mais desenvoltura, a partir do autocontrole, gerenciamento e decréscimo do comportamento disruptivo do mesmo, lembrando que nas escolas brasileiras, o talento das crianças agitadas, 
inteligentes, porém agressivas, termina por se apagar, porque “... a inteligência é a coisa mais disperdiçada do mundo" (SCHIFF, 1994, p.17).

O reconhecimento das altas habilidades, como já foi explicado na página 06, pode ser feito, a partir do uso do Modelo Triádico de Renzulli \& Mönks, (METTRAU, 2000), concebendo-se as relações existentes entre o envolvimento com a tarefa, as habilidades acima da média e a criatividade expressa pela produção do indivíduo.

Os desafios oferecidos ao superdotado necessitam ser em grande número, variados e interessantes, uma vez que o apelo interno deste tipo de pessoa o faz buscar portas de entrada inéditas para "analisar, questionar, associar idéias, situar-se em distintos pontos de vista. É um processo muito rico, que mais tarde se constituirá numa qualidade fundamental para um inventor, um pesquisador..." (CATROUX, 2005, p. 129).

\section{CONSIDERAÇÕES FINAIS}

A partir do trabalho desenvolvido, vale destacar que, tendo a criança da pesquisa sido submetida à intervenção de base cognitivo comportamental, foi possível perceber que a mudança do seu repertório comportamental “... afeta o que está passando, e contribui, continuamente, com as mudanças nas condições situacionais e ambientais, tanto para si como para os demais" (CABALLO, 2006, p. 82).

Finalizando a pesquisa em questão, observa-se não só o decréscimo significativo do comportamento de desafio da criança, como o aumento considerável do processo consciente de que o comportamento de um indivíduo se faz responsabilidade dele mesmo, podendo este senso de controle sobre si, se iniciar em tenra idade.

\section{REFERÊNCIAS}

ANTIPOFF, H. Teste MM. Fundação Nacional de Educação Rural - FEER. Belo Horizonte: Ibérica, 1975.

APA American Psychology Association. 750, First NE, Washington, DC 20002-4242. Telephone: (800) 3365500. TDD/TTY; (202) 336-6123. Disponível em http://www.apa.org/about/contact/copyright/index.aspx. Acesso realizado em 28 de junho de 2014.

BARBOSA, M. C. D. L. Programa de enriquecimento de base cognitivo-comportamental mediando o transtorno obsessivo-compulsivo /TOC de um estudante com altas habilidades na escola regular: um estudo de caso. 2008. Tese (Doutorado em Ciências Médicas), Universidade do Estado do Rio de Janeiro, Rio de Janeiro, 2008. 
BRASIL. Subsídios para organização e funcionamento de serviços de educação especial. Área de altas habilidades. Ministério da Educação e do Desporto, Secretaria de Educação Especial, Série Diretrizes N ${ }^{\circ}$ 9, p. 65, Brasília: MEC, SEESP, 1999.

CABALlO, V. E. Manual de técnicas de terapia e modificação do comportamento. São Paulo: Santos, 2002.

Elementos componentes das Habilidades Sociais. In: CABALLO, V. E. Manual de avaliação e treinamento das habilidades sociais. $1^{\text {a }}$ ed., Rio de Janeiro: SANTOS, p. 17- 97, 2006.

CATROUX, H.. El afán por lo inédito. In: Adda, A; Catroux, H (Eds) Niños superdotados: la inteligencia reconciliada. $1^{\mathrm{a}}$ ed., Barcelona: Ediciones Paidós Ibérica, 2005.

CSIKSZENTMIHALYI, M.. O conteúdo da experiência. In: A descoberta do fluxo: a psicologia do envolvimento com a vida cotidiana. Rio de Janeiro: Rocco, 1999.

DEL PRETTE, Z. A. P.; DEL PRETTE, A. Psicologia das habilidades sociais na infância: teoria e prática. Petrópolis: Vozes, 2005.

DSM - IV. Diagnostic and Statistical Manual of Mental Disorder (Manual Diagnóstico e Estatístico de Transtornos Mentais). (Trad.) Dayse Batista. 4ª ed., Porto Alegre: Artes Médicas Sul, 2000.

GUENTHER, Z. C. Desenvolver capacidades e talentos: um conceito de inclusão. Petrópolis, RJ: Vozes, 2000 .

KAPLAN, H., SADOCK, B. J.; GREBB, J. A. Transtorno obsessivo-compulsivo. In Compêndio de Psiquiatria: ciências do comportamento e psiquiatria clínica. Porto Alegre: Artmed, 2003.

LUISELLI, James, K. Características clínicas e tratamento do transtorno desafiador de oposição. In: SIMÓN, M. A. (Org.) Manual de psicologia clínica infantil e do adolescente: transtornos específicos. $1^{\mathrm{a}}$ ed., São Paulo: Santos, 2005.

METTRAU, M. B.. Inteligência: patrimônio social. Rio de Janeiro: Dunya, 2000.

PADRÓN, I. Las necesidades educativas de todos los superdotados. $1^{\text {a }}$ ed, Madri: Edición Personal, 2000.

RAVEN, J. C. Matrizes progressivas: escala geral. (tradução de Francisco Campos). Rio de Janeiro: CEPA, 2000 .

RENZULLI, J. Escalas para la valoración da las características de comportamiento de los estudiantes superiores. $1^{\text {a }}$ ed., Salamanca: AMARÙ Ediciones, p. 55, 2001.

SERRA-PINHEIRO, M. A.; SCHMITZ, M.; MATTOS, P.; SOUZA, I.. Transtorno desafiador de oposição: uma revisão de correlatos neurobiológicos e ambientais, comorbidades, tratamento e prognóstico. Rev. Bras. Psiquiatria, São Paulo, v. 26, n. 4, 2004.

SCHIFF, M.. A inteligência desperdiçada: desigualdade social, injustiça escolar. Porto Alegre: ARTMED, 1994.

STAKE, R. E. The art of case study research. $1^{\text {a }}$ ed., Thousands Oaks: Sage Publications, 1995.

STALLARD, P. Bons pensamentos, bons sentimentos: manual de terapia cognitivo-comportamental para crianças e adolescentes. Porto Alegre: ARTMED, 2004.

YIN, R. Estudo de caso: planejamento e métodos. $3^{\mathrm{a}}$ ed, Porto Alegre: Bookman, 2005. 